\title{
Gender Variation and Late-life Depression: Findings from a National Survey in the USA
}

\author{
Ethan Siu Leung Cheung ${ }^{1} \mathbb{D} \cdot$ Ada C. Mui ${ }^{1} \mathbb{D}$
}

Accepted: 2 November 2021 / Published online: 8 November 2021

(c) The Author(s), under exclusive licence to Springer Science+Business Media, LLC, part of Springer Nature 2021

\begin{abstract}
Based on the Wave 3 National Social Life, Health, and Aging Project (2015-2016), this study has extensive breadth in examining the roles of multiple stressors (i.e., health-related, social relationship, community) and coping resources (i.e., social participation and social support from family and friends) in explaining depressive symptomatology among a recent cohort of the U.S. national sample of communitydwelling older men $(n=1,431)$ and women $(n=1,673)$. Statistical additive and interactive models were tested. Results from this pre-COVID study serve as a baseline, and show that gender had significant independent and joint effects on stress and coping factors in explaining depressive symptoms. Parallel regression analyses were conducted for each group. Findings suggest that significantly more women $(26.9 \%)$ reported depressive symptoms than men (19.9\%) (CESD-11 score $\geq 9$ ). Multivariate analyses show that unique predictors for older men's depression include less support from friends, more cognitive challenges, and feeling less control in life. For women, less social participation, less emotional support from spouse, greater IADL impairment, and family disharmony were more significantly associated with their depressive symptoms than men's. Contrary to the literature, community factors were not statistically significant in predicting depressive symptoms. Findings suggest that correlates of depressive symptoms impact older women and men differently. Results point to the need for gender-sensitive mental health services and programs to protect community-dwelling older adults in USA against depression, especially in light of the recent COVID era social proximity restrictions.
\end{abstract}

Keywords Depressive Symptoms $\cdot$ Stress $\cdot$ Coping $\cdot$ Gender Variation

Ethan Siu Leung Cheung

sc4447@columbia.edu

Ada C. Mui

acm5@columbia.edu

1 School of Social Work, Columbia University, New York, NY, USA 
In the United States and the Western world, one of the most consistent findings in the aging mental health research is the gender disparity in depression. Compared to older men, women are at a much greater risk of depression (Van de Velde et al., 2010). Demographically, Americans aged 65 and over will grow from 49.2 million in 2016 to 88.5 million by 2050 ; by 2030 , when all baby boomers reach $65,20 \%$ of all Americans will be aged 65 and over (U.S. Census Bureau, 2018). In 2018 for those aged 65 to 74 , there were 21.8 million men and 27.5 million women, and almost twice the number of women (4.1 million) as men (2.2 million) were 85 and over (Roberts et al., 2018). The prevalence of depression among older Americans is approximately $10 \%-13 \%$ for those aged 65 to 79 , and $15 \%-16 \%$ for those aged 80 and over (Federal Interagency Forum on Aging-Related Statistics, 2016). Yet this statistic may be an underestimate as many older adults with depressive symptoms remain undiagnosed and untreated (Helmer, 2014).

With regard to gender differences in depressive symptoms experienced in the older population in the United States, there is limited current information as only a few studies from the most recent cohort of national representative samples were conducted (Ahern \& Hendryx, 2008; Choi \& Ha, 2011). Also, conceptually, the association between multiple levels of stressors, depressive symptoms and gender impact has rarely been studied in a systematic approach. Most of the research from a past cohort of national representative samples supports that gender differences in depression may be just an additive effect of biological, psychological, and social factors. In addition, community level and macro factors were seldom included in their models. Thus, in order to address the knowledge gap, the present study aims to examine the associations between multiple levels of stressors (particularly at the community level), coping resources, and depressive symptoms among older American men and women.

\section{Literature Review}

Extant social science research has examined the association between modifiable psychosocial risk factors and depressive symptoms among community-dwelling older adult populations. Existing data show that older women are at a higher risk of depressive symptoms than older men (Ahern \& Hendryx, 2008; Chen et al., 2014; Choi \& Ha, 2011; Girgus et al., 2017; Jang et al., 2011). Older men and women may express feelings of and cope with depression differently due to norms and values associated with gender role socialization. For instance, some studies have identified the protective effects of social participation against depression. Engaging in volunteering (Choi et al., 2021; Kim \& Pai, 2010; McDonnall, 2011) and religious activities (Chatters et al., 2015; Krause \& Wulff, 2005; Lee \& Ang, 2020; McFarland, 2010) could potentially provide important social and psychological resources and reduce depressive symptoms among older adults, though results have been inconclusive. Older women are likely to benefit more from social participation than men (Ahern \& Hendryx, 2008; Choi et al., 2021; Lee \& Ang, 2020), whereas recent work found that social participation and religious attendance had a protective effect on 
older men's depression but no effect for older women (Chen et al., 2014; Choi \& Ha, 2011).

Moreover, an extant body of literature has identified a negative association between social and emotional support and depressive symptoms (Bélanger et al., 2016; Bui, 2020; Chao et al., 2018; Sonnenberg et al., 2013; Tengku Mohd et al., 2019). The quality of social support could enhance a much-needed sense of social and emotional connectedness as people age (Mui \& Shibusawa, 2008). In terms of gender differences, support from family and friends had a greater protective effect on older women's feelings of depression (Choi \& Ha, 2011).

In addition to coping strategy and resources, research has shown that individuallevel risk factors such as poor health status and functional impairment were associated with depressive symptoms among older Americans (Jang et al., 2005; Kong et al., 2019; Mui \& Kang, 2006). Specifically, activities of daily living (ADL) impairment was associated with depressive symptoms for older women only (Choi \& Ha, 2011). Psychologically, depressive symptoms could be a psychological reaction to physical illnesses or functional limitations (e.g., loss of autonomy, independence, or a sense of control). Also, older adults experiencing instrumental daily living activities (IADL) limitations had higher odds of reporting more depressive symptoms (Kiyoshige et al., 2019; Kong et al., 2019; Li et al., 2019). Potential mechanisms underlying this association include: (a) those with depressive symptoms may experience more burden and complications of chronic conditions, increasing the risk of IADL impairment (Kong et al., 2019); and (b) having depressive symptoms, such as sleep disturbance and loss of appetite, may disincentivize older adults from participating in treatments and preventive approaches for physical illness or functional limitations (Kiyoshige et al., 2019). In terms of gender differences, a study found that older men with IADL disabilities were more likely to develop depressive symptoms than women ( $\mathrm{Li}$ et al., 2019), yet we found no recent studies that focused on the U.S. context.

Besides, cognitive status has been found to be closely related to depressive symptoms. That is, older adults experiencing cognitive impairment or declines are likely to report more depressive symptoms (Borda et al., 2019; Formánek et al., 2020; Köhler et al., 2010; Shin, 2021; Zheng et al., 2018). The explanations provided by most studies are related to changes in medical conditions as a result of depressive symptoms, such as vascular disease and stress (Borda et al., 2019). However, we did not find any study that focused on gender differences in the effect of cognitive status on depressive symptoms.

In terms of social relationship stressors, disharmonious relationships with family and poor friendship quality are risk factors for depressive symptoms. Older adults' dissatisfaction with family relationships predicted more depressive symptoms (Mui \& Kang, 2006). Both the quantity and quality of family support and friendship were also associated with depressive symptoms (Chao et al., 2018; Taylor et al., 2018). Choi and Ha (2011) found that older men and women reported more depressive symptoms when perceived support from family and friends was lower and that perception of less spouse or partner support was correlated to a higher risk of depression for older women only. Similarly, older women aged 85 or older with less social support had a higher risk of depressive symptoms (Lin \& Wang, 2011). This may be 
due to older adults' higher expectations of family solidarity and friendship closeness (Mui \& Shibusawa, 2008). It is also possible that disharmonious family relationships may lead to anxiety among older adults related to not being cared for when needed.

From an environmental gerontology perspective, research has documented the association between subjective evaluation of community environment and depressive symptoms (Chao et al., 2018; Haseda et al., 2018; Kim \& Lee, 2015). Specifically, perceived lack of social cohesion in the community and less outdoor activity were associated with more depressive symptoms (Choi \& Ha, 2011; Cromley et al., 2012; Perez et al., 2015). In addition, higher levels of neighborhood violent crime, unsafe traffic conditions, and poor neighbor relations were also associated with more depressive symptoms among older residents (Ivey et al., 2015; Wilson-Genderson \& Pruchno, 2013). The role of neighborhood characteristics on depressive symptoms of older residents in the community is scientifically interesting and important for age-friendly community design to reduce residents' sense of social isolation. However, to our knowledge, only a few prior studies have examined gender differences in perceived community environmental quality and depressive symptoms. Thus, we included two important variables-perceived community disharmony and safety issues - as community stressors in our model.

In sum, the literature suggests that older adults' mental health may be associated with multiple levels of stressors and resources simultaneously, making it important to examine the relationships systematically. Also, only a few studies examined the role of gender in explaining the relationship between community environments and depressive symptoms. Thus, using a U.S. nationally representative dataset, we intended to revisit gender differences in depression and test the role of gender in explaining the relationship between multiple levels of coping factors, stressors (with a special focus on community stressors), and depressive symptoms.

\section{Conceptual Framework}

In this study, the transactional theory of stress and coping (Aldwin, 1994; Lazarus \& Folkman, 1984) was used to conceptualize and examine the association between stressors, coping resources, depressive symptoms and gender differences. This framework recognizes stress as a complex dynamic process between a person's multiple systems of challenges (health, physical, cognitive, affective, psychological) and one's environment. The theory also emphasizes the significance of individual level stresses and environmental stresses on his or her psychological wellbeing. In other words, the theory suggests that older adults exposed to greater (as opposed to fewer) stressful events would be at an increased risk for depression. Ways of coping with stress are determined by cognitive and behavioral efforts to manage significant challenges (Biggs et al., 2017; Brough et al., 2009; Lazarus \& Folkman, 1984). So even though older adults exposed to more stressful life events might be at increased risk for depression, it has also been shown that as people age, they accrue more coping resources through adapting to stressors, which may have protective effects on depression. Based on this 
framework, we examine the correlates of depressive symptoms in terms of types of stressors (health-related, social relationship, community) and coping resources (social participation, social support from family and friends).

Literature suggests that there are gender differences in world views, life interpretation, social role expectation, quality of relationship with family and friends, life stress management, availability of coping resources, willingness to seek help, and expression of depressive symptoms (Mui \& Shibusawa, 2008). Due to gender role socialization, older women may be more willing to express depressive symptoms (Choi \& Ha, 2011; Mui \& Kang, 2006), and more involved emotionally with their family and friends; thus, women are more susceptible and willing to express emotional impact associated with their social networks. Using a recent national representative sample, we intended to test two hypotheses: (1) compared to older men, older women experience higher levels of depressive symptoms, holding other variables constant; and (2) determinants of depressive symptoms are different between the two gender groups.

\section{Methods}

\section{Data Source}

Data for this secondary research were from Wave 3, National Social Life, Health and Aging Project (NSHAP), which is a U.S. national study that examines how health, mental health, cognitive status, social support, social relationship, and community characteristics relate to the respondents' psychological wellbeing (NORC, 2020). A multistage area probability sampling method was used. Sampling frame was based on the national screening by Health and Retirement in 2004; a sample of 4,400 screened households were eligible for the NSHAP study and $92 \%$ of the households were selected. Two major data collection approaches were adopted: 1) in-home interviews and 2) leave-behind questionnaire. The Wave 2 took place from 2010 through 2011, re-interviewed respondents in Wave 1 and interviewed new eligible respondents. Wave 2 also included the co-residing spouses and partners of the respondents. Using the same data collection approach, a sample of 3,377 respondents were included (NORC, 2020).

In Wave 3, a total sample of 4,777 respondents aged 57 to 85 was interviewed from 2015 through 2016, including re-interviewing 2,409 surviving Wave 2 respondents and a group of 2,368 new respondents who were born between 1948 and 1965. In Wave 3, all questions were asked by in-person interviews and the leave-behind questionnaires, yet separate leave-behind questionnaires were administered for the new and original cohorts of respondents (NORC, 2020). This study used the Wave 3 sample which included the community-dwelling individuals aged 60 and older $(n=3,104)$; this wave was chosen as it is the latest available data in the dataset. Missing data were not dismissed immediately; we carefully decided ways to deal with the missing data based on each of the unique scenarios. 


\section{Measurement of Variables}

Outcome Variable. Depressive symptomatology was operationally defined by a composite score of the 11-item Centre for Epidemiological Studies Depression (CESD-11) scale, which originated from the 20-item CES-D scale (see Table 1). The CESD-11 included: depressive affect (felt depressed, felt lonely, felt sad); positive affect (was happy; enjoyed life); somatic symptoms (did not feel like eating, felt everything was an effort, sleep was restless, could not get going); and inter-personal characteristics (people were unfriendly, felt people disliked self). These items were measured by asking the respondents about the frequency of having the feelings in the past week from rarely or none of the time (0) to most of the time (3). Higher scores denoted higher levels of depressive symptoms and CESD-11 $\geq 9$ is the cutoff point for depression (Choi \& Ha, 2011). Using our data, Cronbach's alphas were computed ( $\alpha=0.80$ for total sample; $\alpha=0.79$ for men; $\alpha=0.82$ for women).

Independent Variables. Independent variables were conceptualized into three categories, which included sociodemographic factors, stressors (health-related stressors, social relationship stressors, community stressors) and coping resources (social participation, social support from family and friends). We used principal component

Table 1 Percentage Distribution of Depressive Symptoms (CESD-11)

\begin{tabular}{|c|c|c|c|}
\hline & & \multicolumn{2}{|l|}{$M(S D)$} \\
\hline & & $\begin{array}{l}\text { Men } \\
(n=1,431)\end{array}$ & $\begin{array}{l}\text { Women } \\
(n=1,673)\end{array}$ \\
\hline \multicolumn{4}{|l|}{ Depressive Symptom } \\
\hline \multicolumn{4}{|l|}{ Depressive Affect } \\
\hline Felt depressed $* * * *$ & & $1.40(.75)$ & $1.56(.84)$ \\
\hline Felt lonely $* * * *$ & & $1.41(.78)$ & $1.63(.92)$ \\
\hline Felt sad $* * * *$ & & $1.53(.80)$ & $1.74(.90)$ \\
\hline \multicolumn{4}{|l|}{ Positive Affect } \\
\hline Was happy & & $.421(.82)$ & $.471(.85)$ \\
\hline Enjoyed life & & $.281(.70)$ & $.319(.75)$ \\
\hline \multicolumn{4}{|l|}{ Somatic Symptoms } \\
\hline Did not feel like eating $* * * *$ & & $1.35(.79)$ & $1.48(.83)$ \\
\hline Felt everything was an effort $*$ & & $1.58(.89)$ & $1.65(.94)$ \\
\hline Sleep was restless $* *$ & & $1.96(1.02)$ & $2.90(1.06)$ \\
\hline Could not get going $* * * *$ & & $1.59(.82)$ & $1.73(.92)$ \\
\hline \multicolumn{4}{|l|}{ Interpersonal Characteristics } \\
\hline People were unfriendly & & $1.24(.60)$ & $1.23(.63)$ \\
\hline Felt people disliked & & $1.19(.54)$ & $1.18(.54)$ \\
\hline $\begin{array}{l}\text { Depressive symptoms (range: } 0-33 \text { ) } \\
\text { **** }\end{array}$ & $4.95(4.85)$ & & $6.08(5.52)$ \\
\hline \multicolumn{4}{|l|}{ Prevalence of depression } \\
\hline Depressed (CES-D $\geq 9)(\%)$ & & 19.87 & 26.85 \\
\hline
\end{tabular}

${ }^{*} p<.05 ; * * p<.01 ; * * * * p<.0001$ 
analysis (PCA) to explore factor structures and cluster factors with the most variance possible by creating composite scores. This approach allowed us to reduce data and make the regression model more parsimonious (Lever et al., 2017). For composite scores, Cronbach's alphas were computed.

Coping resources were operationally defined by five sets of variables: social participation, emotional support from spouse, emotional support from family, emotional support to family, and emotional support from friends. Social participation was a composite score that assessed respondents' participation patterns in three social activities over the past year. Activities included socialization with friends and family, volunteer work, and religious services $(\alpha=0.49)$. Emotional support from spouse $(\alpha=0.68)$ was measured by three items: frequency of respondent opening up to spouse/partner, frequency of respondent relying on spouse/partner, and frequency of spouse/partner understanding the respondent's feeling. Emotional support from family ( $\alpha=0.72$ ) was a composite score of three items: frequency of relying on family; frequency of opening up to family; and frequency of family really understanding the respondent's feeling. Emotional support to family $(\alpha=0.67)$ was also a composite score of three items: family talking about their worries; family requesting help; and respondent understanding the family members' feeling. Emotional support from friends was a single item measure which referred to the frequency of friends really understanding the respondent's feeling. This item and items in the composite scores were measured by a 4-point scale from never (0) to often (3).

Health-related stressors are the first set which is operationally defined by four composite scores: ADL impairment, IADL impairment, cognitive status, and perceived lack of control in life. ADL impairment was measured by difficulty performing seven activities $(\alpha=0.84)$ : dressing, bathing, eating, getting in and out of bed, toileting, walking across room, and walking one block. IADL impairment was measured by difficulty accomplishing eight items $(\alpha=0.85)$ : using a telephone, taking medications, shopping for groceries, preparing meals, performing light housework, managing money, driving car during day, and driving car during night. ADL and IADL items were measured by asking respondents if they experienced difficulty with each activity, ranging from no difficulty (0) to unable to do (3). Cognitive status was measured by respondents' summative scores on the 18-item survey-adapted Montreal Cognitive Assessment (MoCA-SA) $(\alpha=0.74)$. The total score of MoCASA is 20, higher scores representing better cognitive status. Perceived lack of control in life was computed by the 4 -item Perceived Stress Scale (PSS) $(\alpha=0.59)$ : difficulties piling up, confident about my ability, things are going my way, and unable to control important things. Each item was measured by a 4-point scale from rarely or none of the time (1) to most of the time (4).

Social relationship stressors are the second set, which is operationally defined by two composite scores: family disharmony and poor friendship quality. Family disharmony was measured by three items $(\alpha=0.69)$ that explored the respondents' quality of relationship with family members other than spouses: frequency of family criticisms, frequency of "getting on nerves" by family, and frequency of "being let down" by family. Poor friendship quality $(\alpha=0.73)$ was assessed by four items: frequency of friends getting on nerves; frequency of criticism from friends; frequency of "being let down" by friends; and frequency of friends making too many demands. 
For all the items in these three composite scores, respondents rated their experiences on a 4-point scale ranging from Never (0) to Often (3).

Community stressors are the third set, which is operationally defined by community harmony and community safety issues. The variable-community harmony issues $(\alpha=0.62)$ was a composite score defined by three items: people getting along in this area, people in this area sharing the same values, and people in this area can be trusted. Items were measured by a 4-point scale: from strongly disagree (1) to strongly agree (4). The variable-community safety issues was defined by respondents' perception of safety in the community. Higher scores denoted worsening perceived neighborhood safety: from I felt safe (1) to I felt unsafe (5). Sociodemographic factors (i.e., age, gender, marital status, race, household income) were included as controls.

\section{Statistical Analyses}

Hierarchical regression analyses were used to identify the determinants of depressive symptoms. In order to test the two hypotheses, two models were examined: (a) a simple additive model, in which the aforementioned stressors and coping resources would have an additive effect on depressive symptoms; gender was entered last to assess its unique contribution in explaining depressive symptoms, and (b) a model with additive and interactive effects, in which the stressors and coping resources would have interactive effects with gender. Sociodemographic variables (excluding gender), and coping resource variables were entered first as controls. Stressor variables were entered second and the gender variable was entered third. The twoway interaction terms between gender and resource variables, and then gender and stressor variables were entered last because of statistical structural necessity (Cohen et al., 2003).

\section{Results}

As hypothesized, there is evidence of gender differences in depressive symptoms experienced by older men and women in bivariate and multivariate analyses. In Table 1, findings showed that older women reported significantly higher CES-D scores than men (6.08 vs. 4.95). Older women and men also expressed depressive symptoms differently; older women scored significantly higher than men on depressive affect and somatic symptoms. Based on the CES-D cut-off point (CES-D $\geq 9$ ), older women had a significantly higher prevalence of depression than men $(26.85 \%$ vs. $19.87 \%)$.

In Table 2, compared to men, women who participated in this study were older (73.18 vs. 72.67 ), less likely to be married (52.6\% vs. $74.77 \%$ ), and more likely to have low income (58.54\% vs. $44.60 \%$ made less than $50 \mathrm{~K}$ annually). In terms of coping resources, older women scored higher in social participation, emotional support from family, and emotional support to family and friends. On the other hand, older women reported lower scores in emotional support from spouse. In terms of 
Table 2 Descriptive Statistics of Variables in the Study

\begin{tabular}{|c|c|c|}
\hline \multirow[b]{2}{*}{ Characteristics } & \multicolumn{2}{|l|}{ Percentage } \\
\hline & $\begin{array}{l}\text { Men } \\
(n=1,431)\end{array}$ & $\begin{array}{l}\text { Women } \\
(n=1,673)\end{array}$ \\
\hline Mean age (SD) & $72.67(8.27)$ & $73.18(8.30)$ \\
\hline \multicolumn{3}{|l|}{ Age groups } \\
\hline $60-69$ & 39.69 & 38.02 \\
\hline $70-79$ & 37.81 & 37.96 \\
\hline 80 and above & 22.50 & 24.03 \\
\hline \multicolumn{3}{|l|}{ Marital status $* * * *$} \\
\hline Married & 74.77 & 52.60 \\
\hline \multicolumn{3}{|l|}{ Race } \\
\hline White/Caucasian & 77.26 & 75.19 \\
\hline Black/African American & 14.11 & 16.30 \\
\hline Asian, Pacific islander, American Indians & 8.63 & 8.51 \\
\hline \multicolumn{3}{|l|}{ Household income $* * * *$} \\
\hline $0-49,999$ & 44.60 & 58.54 \\
\hline $50,000-99,000$ & 33.31 & 29.47 \\
\hline \multirow[t]{2}{*}{100,000 or higher } & 22.09 & 11.99 \\
\hline & $M(S D)$ & $M(S D)$ \\
\hline \multicolumn{3}{|l|}{ Coping Resources } \\
\hline Social participation $* * * *$ & $5.69(3.35)$ & $6.33(3.32)$ \\
\hline Emotional support from spouse $* * * *$ & $6.56(3.31)$ & $4.44(4.01)$ \\
\hline Emotional support from family $* * * *$ & $5.64(2.96)$ & $6.34(2.88)$ \\
\hline Emotional support to family $* * * *$ & $5.31(2.72)$ & $5.79(2.68)$ \\
\hline Emotional support from friends $* * * *$ & $1.90(.87)$ & $2.22(.79)$ \\
\hline \multicolumn{3}{|l|}{ Health-Related Stressors } \\
\hline Cognitive status $*$ & $13.34(3.54)$ & $13.61(3.71)$ \\
\hline ADL impairment $* *$ & $1.15(2.45)$ & $1.42(2.74)$ \\
\hline IADL impairment $* * * *$ & $1.66(3.48)$ & $2.35(3.92)$ \\
\hline Perceived lack of control in life & $7.69(3.95)$ & $7.73(3.90)$ \\
\hline \multicolumn{3}{|l|}{ Social Relationship Stressors } \\
\hline Family disharmony $* *$ & $2.62(2.05)$ & $2.89(2.12)$ \\
\hline Poor friendship quality $*$ & $2.75(2.28)$ & $2.65(2.76)$ \\
\hline \multicolumn{3}{|l|}{ Community Stressors } \\
\hline Community harmony issue & $6.97(3.28)$ & $7.05(3.17)$ \\
\hline Community safety issue & $4.77(.60)$ & $4.77(.62)$ \\
\hline
\end{tabular}

${ }^{*} p<.05 ; * * p<.01 ; * * * * p<.0001$

health-related stressors, older women scored better scores in cognitive status, as well as had fewer ADL and IADL impairments. With regard to social relationship stressors, older women scored higher in perceived family disharmony, and men scored higher in poor spouse relationship and poor friendship quality. 
To test for the effects of gender in predicting depressive symptoms, regression was conducted with sociodemographic factors, coping resources, and stressors entered into the model in hierarchical order, then gender variable was entered last. The model explained $23.8 \%$ of the variance in depressive symptoms, $F$ $(19,2097)=34.51, p<0.0001$ (see Table 3). The results showed that each set of independent variables made a significant contribution in explaining depressive symptoms: sociodemographic variables (excluding gender) accounted for $6.0 \%$ $(p<0.0001)$; coping resource variables accounted for another $6.9 \%(p<0.0001)$; and stressor variables, accounted for an additional $10.7 \%(p<0.0001)$. After controlling for all other variables in the model, gender uniquely added $0.1 \%(p<0.0001)$ explained variance in depressive symptoms. Findings suggest that there was gender difference in depressive symptoms experienced, with older women scoring a higher level of depressive symptoms, everything being equal. Thus, the first hypothesis was supported.

In addition to analyzing differences in the levels of depressive symptoms between older women and men, reflected in the additive model, a second strategy was to analyze additive and interactive effects. The interactive model was significant and it explained $24.2 \%$ of the variance in depressive symptoms, $F(31,2085)=21.46$, $p<0.0001$ (see Table 3). Among the two-way interaction terms between gender, stressors, coping resource factors, only one interaction term (gender by emotional support from the spouse) was significant $(p<0.05)$ to the variance of depressive symptoms. This finding indicated that the impact of emotional support by spouse varied by gender of the respondents. Specifically, the effect of spousal support in predicting depressive symptoms is stronger among older women, than men $(b=0.089)$. This finding also indicated that one overall regression line was not the best fit for the data, therefore, parallel regression analyses were conducted for each gender group.

Table 4 shows that the determinants of depressive symptoms varied by gender group. Thus, the second hypothesis was supported. For older men, the model explained $25.6 \%$ of the variance in depressive symptoms score, $F$ $(18,1022)=19.58, p<0.0001$. The model for older women explained $22.2 \%$ of variances, $F(17,1058)=17.74, p<0.0001$. These findings indicate that the sociodemographic, stressors, coping resources variables influenced older men and women in a different manner as indicated by the size of the unstandardized regression coefficients of the respective predictors. The differences between the respective slopes were tested by $\mathrm{T}$-test. The respective slopes were different statistically at less than the 0.05 level. Young-old was associated with a higher level of depressive symptoms for both groups but had greater impact on women ( $b=-0.040$ vs. $b=-0.046$ ); married women were more depressed but marital status did not predict depressive symptoms on men; older White men reported higher level of depressive symptoms than Black men; White women scored more depressive symptoms than Asian American women; lower household income had a stronger effect on women $(b=-0.740)$ than on men $(b=-0.366)$. In terms of coping resources, social participation had stronger negative effect on older women $(b=-0.196)$ than on men $(b=-0.157)$. Also, lower level of emotional support from spouse affected women more than men $(b=-0.189$ vs. $b=-0.179)$. Inability to 
Table 3 Hierarchical Regression Analyses Testing Additive and Interactive Effects of Gender by Stress and Coping Resources

\begin{tabular}{|c|c|c|}
\hline Predictor Variables & $b(S E)$ & $R^{2}(\%) \& R^{2}$ Change \\
\hline \multicolumn{3}{|l|}{ Sociodemographic (Step 1) } \\
\hline Age & $-.032(.013) *$ & \\
\hline Marital status & $-1.21(.226) * * * *$ & \\
\hline Black/African American (white =0) & $-.674(.438)$ & \\
\hline $\begin{array}{l}\text { Asian, Pacific Islanders, American Indians } \\
(\text { White }=0)\end{array}$ & $-.060(.372)$ & \\
\hline Household income & $-1.29(.148)$ & \\
\hline R-square at this step & & $.060 * * * *$ \\
\hline \multicolumn{3}{|l|}{ Coping Resources (Step 2) } \\
\hline Social participation & $-.222(.042) * * * *$ & \\
\hline Emotional support from spouse & $-.227(.030) * * * *$ & \\
\hline Emotional support from family & $-.061(.067)$ & \\
\hline Emotional support to family & $-.288(.075) * * * *$ & \\
\hline Emotional support from friends & $-.398(.134) * *$ & \\
\hline Increment of R-square at this step & & $.069 * * * *$ \\
\hline \multicolumn{3}{|l|}{ Health-Related Stressors (Step 3) } \\
\hline Cognitive status & $-.111(.041) * *$ & \\
\hline ADL impairment & $.264(.060) * * * *$ & \\
\hline IADL impairment & $.230(.046) * * * *$ & \\
\hline Perceived lack of control in life & $.062(.035)$ & \\
\hline \multicolumn{3}{|l|}{ Social Relationship Stressors } \\
\hline Family disharmony & $.514(.056) * * * *$ & \\
\hline Poor friendship quality & $.107(.052) * * * *$ & \\
\hline \multicolumn{3}{|l|}{ Community Stressors } \\
\hline Community harmony issue & $.012(.047)$ & \\
\hline Community safety issue & $.050(.182)$ & \\
\hline Increment of $R^{2}$ at this step & & $.107 * * * *$ \\
\hline \multicolumn{3}{|l|}{ Gender (Step 4) } \\
\hline Female $=1$ & $.409(.220) *$ & \\
\hline Increment of $\mathrm{R}^{2}$ at this step & & $.001 * * * *$ \\
\hline \multicolumn{3}{|l|}{ Interaction terms $(\text { Step } 5)^{\mathrm{a}}$} \\
\hline Emotional support from spouse $\mathrm{x}$ Gender & $.089(.034) *$ & \\
\hline Increment of $\mathrm{R}^{2}$ at this step & & $.002 * * * *$ \\
\hline R-square & & $.239 * * * *$ \\
\hline Adjusted R-square & & $.232 * * * *$ \\
\hline
\end{tabular}

This significant interaction term is shown on this Table

$b$ is unstandardized regression coefficient, standard error is in parentheses ${ }^{*} p<.05 ; * * p<.01 ; * * * * p<.0001$.

aAmong all the two-way interaction terms between gender and stressors; gender and coping resource factors, only "Gender by Emotional support from spouse" was significant $(p=.036)$ 
Table 4 Regression Analyses of Depressive Symptoms by Gender

\begin{tabular}{|c|c|c|}
\hline \multirow[b]{2}{*}{ Variables } & \multirow{2}{*}{$\frac{\text { Men }}{b(S E)}$} & \multirow{2}{*}{$\frac{\text { Women }}{b(S E)}$} \\
\hline & & \\
\hline \multicolumn{3}{|l|}{ Sociodemographic } \\
\hline Age $(60-95)$ & $-.040(.018) *$ & $-.046(.022) *$ \\
\hline Marital status (Married = 1) & $.062(.469)$ & $1.77(.577) * *$ \\
\hline Black/African Americans (White $=0$ ) & $-1.34(.435) * *$ & $-1.15(.353)$ \\
\hline $\begin{array}{l}\text { Asian, Pacific Islander, American Indi- } \\
\text { ans (White }=0 \text { ) }\end{array}$ & $-.004(.504)$ & $-1.25(.572) *$ \\
\hline Household income $(1-3)$ & $-.366(.180) *$ & $-.740(.241) * *$ \\
\hline \multicolumn{3}{|l|}{ Coping Resources } \\
\hline Social participation $(0-33)$ & $-.157(.052) * *$ & $-.196(.061) * *$ \\
\hline Emotional support from spouse $(0-9)$ & $-.179(.039) * * * *$ & $-.189(.043) * * * *$ \\
\hline Emotional support from family $(0-9)$ & $.047(.082)$ & $.051(.102)$ \\
\hline Emotional support to family $(0-9)$ & $-.269(.094) * *$ & $-.253(.107) *$ \\
\hline Emotional support from friends $(0-3)$ & $-.344(.162) *$ & $-.169(.205)$ \\
\hline \multicolumn{3}{|l|}{ Health-Related Stressors } \\
\hline Cognitive status $(0-20)$ & $-.155(.048) * *$ & $-.093(.052)$ \\
\hline ADL impairment $(0-21)$ & $.340(.081) * * * *$ & $.225(.088) *$ \\
\hline IADL impairment $(0-24)$ & $.162(.061) * *$ & $.254(.069) * * * *$ \\
\hline Perceived lack of control in life $(0-16)$ & $.107(.047) *$ & $.033(.052)$ \\
\hline \multicolumn{3}{|l|}{ Social Relationship Stressors } \\
\hline Family disharmony $(0-9)$ & $.461(.078) * * * *$ & $.547(.090) * * * *$ \\
\hline Poor friendship quality $(0-12)$ & $.101(.068)$ & $.137(.079)$ \\
\hline \multicolumn{3}{|l|}{ Community Stressors } \\
\hline Community harmony issue $(0-15)$ & $-.050(.064)$ & $.053(.069)$ \\
\hline Community safety issue $(0-5)$ & $.010(.243)$ & $.177(.271)$ \\
\hline R-square & $.256^{* * * *}$ & $.222 * * * *$ \\
\hline Adjusted R-square & $.243 * * * *$ & $.209 * * * *$ \\
\hline $\mathrm{F}$ & 19.58 & 17.74 \\
\hline
\end{tabular}

$b$ is unstandardized regression coefficient, standard error is in parentheses ${ }^{*} p<.05 ; * * p<.01 ; * * * * p<.0001$

provide emotional support to family had stronger effect on older men $(b=-0.269)$ than on women $(b=-0.253)$. Furthermore, older men felt more depressed if they had less emotional support from friends $(b=-0.344)$, and yet this had no effect on women. With regard to stressors, poor cognitive status $(b=-0.155)$ and perceived lack of control in life $(b=0.107)$ were associated with more depressive symptoms among older men only. ADL impairments had a much stronger effect on older men $(b=0.340)$ than on women $(b=0.225)$, while older women were relatively more depressed if they had more IADL impairments $(b=0.254$ vs. $b=0.162)$. In terms of social relationship stressors, family disharmony had much greater impact for older women $(b=0.547)$ than men $(b=0.461)$. 


\section{Discussion and Implications}

Findings suggest differences in depressive symptoms experienced by older men and women living in the US communities. The mean depressive symptom score for older women was significantly higher than men, with one in four women as compared to one in five men having clinically significant depressive symptoms, which is consistent with the literature (Chen et al., 2014; Choi \& Ha, 2011). Statistically, older men and women are different; however, substantively both groups are at risk of depression because of the high prevalence rates of clinically depressive symptoms among both. Also, the observed differences in the level of depressive symptoms between the two gender groups could be due to older men being less willing to admit their feelings of depression (Mui \& Kang, 2006).

Analyses found both commonalities and differences in the predictors of depression between the older men and women samples, and that stressors and coping factors had differential impact on depressive symptom scores of each group, suggesting different coping and stress management skills for men and women. In terms of coping resources, social participation and emotional support from spouse were common protective factors for both older men and women, but had stronger effect for older women which is consistent with prior work (Ahern \& Hendryx, 2008; Chen et al., 2014). For both groups, support to family was associated with fewer depressive symptoms even though the impact was greater for men, implying they are more depressed when they cannot provide help to family. To our knowledge, prior work did not examine this intergenerational relationship, but this association implied that older men and women needed to feel important and included in their family system, especially older men. In terms of friendship support, for older men only, perceived support from friends was a protective factor of depressive symptoms. The support from friends is extremely important for older men's psychological well-being especially after retirement and reduction of social network size (Mui \& Shibusawa, 2008).

With regard to health-related stressors, cognitive decline and perceived lack of control in life predicted more depressive symptoms for older men only. Being dependent and inability to control life situations runs counter to men's masculine identity and gender role expectation. By the same logic, ADL impairment also had greater impact for older men than older women because ADL impairment compromised older men's sense of autonomy. IADL impairment was in a stronger association with depressive symptoms of older women than men. Older women's primary role in the household usually would be running errands and taking care of tangible needs of family, thus IADL limits may compromise older women's caretaking role in the family. Policies and programs focusing on mobility strengthening will increase flexibility and confidence in ADL abilities. Also, helping older women adapt IADLs to physiological changes will allow them to keep active in helping family, at a level they can do competently, and help them learn to delegate some IADL activities. Cultivating volunteerism and meaningful club leadership roles for older men could help ameliorate perceived lack of control. 
In terms of social relationship stressor, family disharmony was associated with more depressive symptoms for both groups but had greater impact for older women. This corresponds to previous studies on intergenerational relationship and depression (Choi \& Ha, 2011; Mui \& Shibusawa, 2008). This may be explained by variations in perspective and coping strategies between older men and women. Older women feel depressed when the intergenerational relationship is not harmonious, and may perceive they are responsible for taking care of everyone and keeping the family together, contributing to greater mental and emotional stress. Group and individual therapy focused on communication and boundary skills training for women can increase sense of self-control and progress to understanding each other, strengthening relationships.

With regard to community stressors, community harmony and safety issues were included in the model because community characteristics were found to be risk factors for depression in prior research (Ivey et al., 2015; Wilson-Genderson $\&$ Pruchno, 2013). However, in contrast with the previous literature, our additive analyses suggested that community stressors were statistically insignificant in predicting depressive symptoms. Similarly, our findings on parallel analyses could not find any association between community stressors and depressive symptoms for either gender group. One speculation is that although community stressors could have yielded protective effects against depression owed to better coping resources and meaningful engagements, as previous literature has suggested (Choi et al., 2015; Cromley et al., 2012; Perez et al., 2015), individual stressors (i.e., health and sociodemographic) may be more directly and significantly predicting with depressive symptoms. In other words, older adults may engage less in community environments for meaningful activities when suffering from health-related and social relationship stressors. These findings also pointed that future research is warranted to study the role of more age-friendly community characteristics on older adults' mental health.

In terms of sociodemographic factors, although older adults in general had higher depression, young-old and low income were risk factors of more depressive symptoms for both groups, and these factors had greater impact for older women. This would be consistent with the literature (Chen et al., 2014; Choi \& Ha, 2011). Old-old persons may be more resilient and content than young-old persons, and better able to cope with life stressors. Old-old persons are life champions and may have learned to lower life expectations. Being married was associated with higher levels of depression for older women, but not for men. One possible explanation is that married women may be more susceptible to emotional distresses associated with multiple role involvement and competing demands from family and work. White men reported more depressive symptoms than Black men, and White women expressed a higher level of depression than Asian American women. Racial differences may be a reflection of differences in coping strategies, stress threshold, cultural interpretation and expression of depressive symptoms. More in-depth investigation is warranted to examine the association between culture and depression. Mental health providers should consider developing services where old-old persons can pass on life lessons and resiliency skills to the young-old (Mui et al., 2013). Also, regular benefits screenings, health insurance and financial literacy classes can give important skills and empowerment to 
managing limited financial resources. Caregiver support for older women as they age is crucial as they carry the role of caregiver for their husbands, families, and communities, especially religious organizations.

There are limitations to this study. First, the direction of association between variables cannot be inferred because we used only cross-sectional data. Second, gender differences in terms of help seeking behaviors and attitudes toward mental health service utilization could not be examined because these variables were not measured in the original study. Third, there may also be measurement issues in the community stressors. Important age-friendly community indicators such as neighborhood walkability, proximity to social amenities, and accessibility of public transportation were not available in the original study.

In sum, findings from this U.S. national representative sample provide important direction for aging mental health programs and gender sensitive practices. The findings of this study may serve as a pre-COVID-19 baseline data that can be used to compare aging mental health and gender difference among older populations living in the community after the pandemic is over. The depression risk factors associated with the pandemic lockdown such as community disengagement, social isolation, loneliness, social disconnectedness, lack of physical activities, worsening health, and losses of family and friends during the pandemic should be carefully evaluated. Health care professionals desire to provide creative and innovative individual and group mental health promotion and anti-depression services in the virtual environments across the globe. Education on depression risk factors, symptoms, treatment and coping skills is very important for older adults. Gender specific groups can help to further peer support and growth in emotional awareness and processing as a protector for depression.

A pressing question resulting from the pandemic is how global and local communities can support our more vulnerable older populations psychologically when modern families are not in proximity. Mental health can be an issue at any age, but the technological advances that can bridge familial and social deserts tend to be favored by the young. One of the lessons learned from the pandemic is that older adults need to be competent with technology to access socialization and mental health resources remotely. For those with limited experience and knowledge of technology, there needs to be more local community trainings especially designed for older adults on use of effective technology that provides support during times of stress and isolation.

Funding None reported.

Data Availability The data that support the findings of this study are openly available in Wave 3, National Social life, Health, and Aging Project at https://www.icpsr.umich.edu/web/NACDA/studies/36873.

\section{Declarations}

Conflict of Interest None reported.

Informed Consent None. 
Ethical Treatment of Experimental Subjects (Animals and Humans) No experimental treatment was conducted on either human or animal subjects in this study.

\section{References}

Ahern, M. M., \& Hendryx, M. (2008). Community participation and the emergence of late-life depressive symptoms: Differences between women and men. Journal of Women's Health (2002), 17(9), 1463-1470. https://doi.org/10.1089/jwh.2007.0752

Aldwin, C. M. (1994). Stress, coping, and development: An integrative perspective (pp. xvii, 331). Guilford Press.

Bélanger, E., Ahmed, T., Vafaei, A., Curcio, C. L., Phillips, S. P., \& Zunzunegui, M. V. (2016). Sources of social support associated with health and quality of life: A cross-sectional study among Canadian and Latin American older adults. British Medical Journal Open, 6(6), e011503. https://doi.org/10. 1136/bmjopen-2016-011503

Biggs, A., Brough, P., \& Drummond, S. (2017). Lazarus and Folkman's Psychological Stress and Coping Theory. In The Handbook of Stress and Health (pp. 349-364). John Wiley \& Sons, Ltd. https://doi. org/10.1002/9781118993811.ch21

Borda, M. G., Santacruz, J. M., Aarsland, D., Camargo-Casas, S., Cano-Gutierrez, C. A., Suárez-Monsalve, S., Campos-Fajardo, S., \& Pérez-Zepeda, M. U. (2019). ASSOCIATION OF DEPRESSIVE SYMPTOMS AND SUBJECTIVE MEMORY COMPLAINTS WITH THE INCIDENCE OF COGNITIVE IMPAIRMENT IN OLDER ADULTS WITH HIGH BLOOD PRESSURE. European Geriatric Medicine, 10(3), 413-420. https://doi.org/10.1007/s41999-019-00185-1

Brough, P., O’Driscoll, M., Kalliath, T., Cooper, C. L., \& Poelmans, S. A. Y. (2009). Workplace psychological health: Current research and practice (pp. xiv, 207). Edward Elgar Publishing. https://doi. org/10.4337/9781781952672

Bui, B. K. H. (2020). The relationship between social network characteristics and depressive symptoms among older adults in the United States: Differentiating between network structure and network function. Psychogeriatrics: The Official Journal of the Japanese Psychogeriatric Society, 20(4), 458-468. https://doi.org/10.1111/psyg.12530

Chao, Y.-Y., Katigbak, C., Zhang, N. J., \& Dong, X. (2018). Association Between Perceived Social Support and Depressive Symptoms Among Community-Dwelling Older Chinese Americans. Gerontology \& Geriatric Medicine, 4, 2333721418778194. https://doi.org/10.1177/2333721418778194

Chatters, L. M., Taylor, R. J., Woodward, A. T., \& Nicklett, E. J. (2015). Social Support from Church and Family Members and Depressive Symptoms among Older African Americans. The American Journal of Geriatric Psychiatry : Official Journal of the American Association for Geriatric Psychiatry, 23(6), 559-567. https://doi.org/10.1016/j.jagp.2014.04.008

Chen, R., A. Simon, M., Dong, X., \& 1 Rush Institute for Healthy Aging, Rush University Medical Center, Chicago, IL 60612, USA; (2014). Gender Differences in Depressive Symptoms in U.S. Chinese Older Adults. AIMS Medical Science, 1(1), 13-27. https://doi.org/10.3934/Medsci.2014.1.13

Choi, E., Han, K.-M., Chang, J., Lee, Y. J., Choi, K. W., Han, C., \& Ham, B.-J. (2021). Social participation and depressive symptoms in community-dwelling older adults: Emotional social support as a mediator. Journal of Psychiatric Research, 137, 589-596. https://doi.org/10.1016/j.jpsychires.2020. 10.043

Choi, N. G., \& Ha, J.-H. (2011). Relationship between spouse/partner support and depressive symptoms in older adults: Gender difference. Aging \& Mental Health, 15(3), 307-317. https://doi.org/10.1080/ 13607863.2010 .513042

Choi, N. G., Kim, J., DiNitto, D. M., \& Marti, C. N. (2015). Perceived Social Cohesion, Frequency of Going Out, and Depressive Symptoms in Older Adults: Examination of Longitudinal Relationships. Gerontology \& Geriatric Medicine, 1, 2333721415615478. https://doi.org/10.1177/2333721415615478

Cohen, J., Cohen, P., West, S. G., \& Aiken, L. S. (2003). Applied multiple regression/correlation analysis for the behavioral sciences, 3rd ed (pp. xxviii, 703). Lawrence Erlbaum Associates Publishers.

Cromley, E. K., Wilson-Genderson, M., \& Pruchno, R. A. (2012). Neighborhood characteristics and depressive symptoms of older people: Local spatial analyses. Social Science \& Medicine (1982), 75(12), 2307-2316. https://doi.org/10.1016/j.socscimed.2012.08.033 
Federal Interagency Forum on Aging-Related Statistics. (2016). Older Americans 2016: Key Indicators of Well-Being. https://agingstats.gov/docs/LatestReport/Older-Americans-2016-Key-Indicators-ofWellBeing.pdf

Formánek, T., Csajbók, Z., Wolfová, K., Kučera, M., Tom, S., Aarsland, D., \& Cermakova, P. (2020). Trajectories of depressive symptoms and associated patterns of cognitive decline. Scientific Reports, 10(1), 20888. https://doi.org/10.1038/s41598-020-77866-6

Girgus, J. S., Yang, K., \& Ferri, C. V. (2017). The Gender Difference in Depression: Are Elderly Women at Greater Risk for Depression Than Elderly Men? Geriatrics, 2(4), 35. https://doi.org/10. 3390/geriatrics2040035

Haseda, M., Kondo, N., Takagi, D., \& Kondo, K. (2018). Community social capital and inequality in depressive symptoms among older Japanese adults: A multilevel study. Health \& Place, 52, 8-17. https://doi.org/10.1016/j.healthplace.2018.04.010

Helmer, J. (2014). What Is Depression-Symptoms and Treatment. AARP - What Is Depression - Symptoms and Treatment. https:/www.aarp.org/health/conditions-treatments/info-09-2013/depression-what-youshould-know.html

Ivey, S. L., Kealey, M., Kurtovich, E., Hunter, R. H., Prohaska, T. R., Bayles, C. M., \& Satariano, W. A. (2015). Neighborhood characteristics and depressive symptoms in an older population. Aging \& Mental Health, 19(8), 713-722. https://doi.org/10.1080/13607863.2014.962006

Jang, Y., Borenstein, A. R., Chiriboga, D. A., \& Mortimer, J. A. (2005). Depressive symptoms among African American and white older adults. The Journals of Gerontology. Series B, Psychological Sciences and Social Sciences, 60(6), P313-P319. https://doi.org/10.1093/geronb/60.6.p313

Jang, Y., Kim, G., \& Chiriboga, D. A. (2011). Gender differences in depressive symptoms among older Korean American immigrants. Social Work in Public Health, 26(1), 96-109. https://doi.org/10. 1080/10911350902987003

Kim, J., \& Pai, M. (2010). Volunteering and Trajectories of Depression. Journal of Aging and Health, 22(1), 84-105. https://doi.org/10.1177/0898264309351310

Kim, K., \& Lee, M. (2015). Depressive Symptoms of Older Adults Living Alone: The Role of Community Characteristics. International Journal of Aging \& Human Development, 80(3), 248-263. https://doi.org/10.1177/0091415015590315

Kiyoshige, E., Kabayama, M., Gondo, Y., Masui, Y., Inagaki, H., Ogawa, M., Nakagawa, T., Yasumoto, S., Akasaka, H., Sugimoto, K., Ikebe, K., Arai, Y., Ishizaki, T., Rakugi, H., \& Kamide, K. (2019). Age group differences in association between IADL decline and depressive symptoms in community-dwelling elderly. BMC Geriatrics, 19(1), 309. https://doi.org/10.1186/s12877-019-1333-6

Köhler, S., van Boxtel, M. P. J., van Os, J., Thomas, A. J., O’Brien, J. T., Jolles, J., Verhey, F. R. J., \& Allardyce, J. (2010). Depressive symptoms and cognitive decline in community-dwelling older adults. Journal of the American Geriatrics Society, 58(5), 873-879. https://doi.org/10.1111/j.15325415.2010.02807.x

Kong, D., Solomon, P., \& Dong, X. (2019). Depressive Symptoms and Onset of Functional Disability Over 2 Years: A Prospective Cohort Study. Journal of the American Geriatrics Society, 67(S3), S538-S544. https://doi.org/10.1111/jgs.15801

Krause, N., \& Wulff, K. M. (2005). Friendship Ties in the Church and Depressive Symptoms: Exploring Variations by Age. Review of Religious Research, 46(4), 325-340. https://doi.org/10.2307/3512164

Lazarus, R. S., \& Folkman, S. (1984). Stress, Appraisal, and Coping. Springer Publishing Company.

Lee, H., \& Ang, S. (2020). Productive Activities and Risk of Cognitive Impairment and Depression: Does the Association Vary by Gender? Sociological Perspectives: SP: Official Publication of the Pacific Sociological Association, 63(4), 608-629. https://doi.org/10.1177/0731121419892622

Lever, J., Krzywinski, M., \& Altman, N. (2017). Principal component analysis. Nature Methods, 14(7), 641-642. https://doi.org/10.1038/nmeth.4346

Li, M., Yang, Y., Pang, L., Wu, M., Wang, Z., Fu, Y., \& Li, K. (2019). Gender-specific associations between activities of daily living disability and depressive symptoms among older adults in China: Evidence from the China Health and Retirement Longitudinal Study. Archives of Psychiatric Nursing, 33(6), 160-166. https://doi.org/10.1016/j.apnu.2019.08.010

Lin, P.-C., \& Wang, H.-H. (2011). Factors associated with depressive symptoms among older adults living alone: An analysis of sex difference. Aging \& Mental Health, 15(8), 1038-1044. https://doi.org/ 10.1080/13607863.2011.583623

McDonnall, M. C. (2011). The Effect of Productive Activities on Depressive Symptoms Among Older Adults With Dual Sensory Loss. Research on Aging, 33(3), 234-255. https://doi.org/10.1177/ 0164027511399106 
McFarland, M. J. (2010). Religion and Mental Health Among Older Adults: Do the Effects of Religious Involvement Vary by Gender? The Journals of Gerontology Series b: Psychological Sciences and Social Sciences, 65B(5), 621-630. https://doi.org/10.1093/geronb/gbp112

Mui, A. C., Glajchen, M., Chen, H., \& Sun, J. (2013). Developing an Older Adult Volunteer Program in a New York Chinese Community: An Evidence-Based Approach. Ageing International, 38(2), 108-121. https://doi.org/10.1007/s12126-012-9160-5

Mui, A. C., \& Kang, S.-Y. (2006). Acculturation stress and depression among Asian immigrant elders. Social Work, 51(3), 243-255. https://doi.org/10.1093/sw/51.3.243

Mui, A. C., \& Shibusawa, T. (2008). INFORMAL SUPPORT AND INTERGENERATIONAL RELATIONSHIPS. In Asian American Elders in the Twenty-first Century (pp. 106-126). Columbia University Press. https://www.jstor.org/stable/10.7312/mui-13590.10

NORC. (2020). National Social Life, Health, and Aging Project (NSHAP) | NORC.org. https://www.norc. org/Research/Projects/Pages/national-social-life-health-and-aging-project.aspx

Perez, L. G., Arredondo, E. M., McKenzie, T. L., Holguin, M., Elder, J. P., \& Ayala, G. X. (2015). Neighborhood Social Cohesion and Depressive Symptoms Among Latinos: Does Use of Community Resources for Physical Activity Matter? Journal of Physical Activity \& Health, 12(10), 1361-1368. https://doi.org/10.1123/jpah.2014-0261

Roberts, A. W., Ogunwole, S. U., Blakeslee, L., \& Rabe, M. A. (2018). The Population 65 Years and Older in the United States: 2016. https://www.census.gov/content/dam/Census/library/publications/ 2018/acs/ACS-38.pdf

Shin, M. (2021). Depressive symptoms with cognitive dysfunction increase the risk of cognitive impairment: Analysis of the Korean Longitudinal Study of Aging (KLoSA), 2006-2018. International Psychogeriatrics, 33(8), 791-801. https://doi.org/10.1017/S1041610220003622

Sonnenberg, C. M., Deeg, D. J. H., van Tilburg, T. G., Vink, D., Stek, M. L., \& Beekman, A. T. F. (2013). Gender differences in the relation between depression and social support in later life. International Psychogeriatrics, 25(1), 61-70. https://doi.org/10.1017/S1041610212001202

Taylor, H. O., Taylor, R. J., Nguyen, A. W., \& Chatters, L. (2018). Social Isolation, Depression, and Psychological Distress among Older Adults. Journal of Aging and Health, 30(2), 229-246. https://doi. org/10.1177/0898264316673511

Tengku Mohd, T. A. M., Yunus, R. M., Hairi, F., Hairi, N. N., \& Choo, W. Y. (2019). Social support and depression among community dwelling older adults in Asia: A systematic review. British Medical Journal Open, 9(7), e026667. https://doi.org/10.1136/bmjopen-2018-026667

U.S. Census Bureau. (2018). Older People Projected to Outnumber Children. https://www.census.gov/ newsroom/press-releases/2018/cb18-41-population-projections.html

Van de Velde, S., Bracke, P., \& Levecque, K. (2010). Gender differences in depression in 23 European countries. Cross-national variation in the gender gap in depression. Social Science \& Medicine, 71(2), 305-313. https://doi.org/10.1016/j.socscimed.2010.03.035

Wilson-Genderson, M., \& Pruchno, R. (2013). Effects of neighborhood violence and perceptions of neighborhood safety on depressive symptoms of older adults. Social Science \& Medicine, 1982(85), 43-49. https://doi.org/10.1016/j.socscimed.2013.02.028

Zheng, F., Zhong, B., Song, X., \& Xie, W. (2018). Persistent depressive symptoms and cognitive decline in older adults. The British Journal of Psychiatry: THe Journal of Mental Science, 213(5), 638-644. https://doi.org/10.1192/bjp.2018.155

Publisher's Note Springer Nature remains neutral with regard to jurisdictional claims in published maps and institutional affiliations.

Ethan Siu Leung Cheung MA, MSW, is a doctoral student at the Columbia University School of Social Work. His research interests include aging-in-place, age-friendly community development and environmental gerontology.

Ada C. Mui PhD, is a professor at the Columbia University School of Social Work. Her research interests include productive aging, aging mental health, dementia caregiving, and validation of dementia screening instruments for use among community-dwelling older Chinese American and immigrant populations. 